\title{
Cuidados no pós-operatório do transplante cardíaco
}

\author{
Alfredo I. FIORELLI ${ }^{\star}$, Noedir A. G. STOLF*.
}

RBCCV 44205-286

FIORELLI, A. I. \& STOLF, N. A. G. - Cuidados no pós-operatório do transplante cardiaco. Rev. Bras. Cir. Cardiovasc., 11 (1): 30-38, 1996.

RESUMO: Os autores discutem os principais aspectos envolvidos no pós-operatório imediato do transplante cardíaco, ressaltando: monitorização pós-operatória, evolução hemodinâmica, arritimias, controle hidroeletrolítico, alteraçōes gastrintestinais, função renal, suporte ventilatório, antibioticoprofilaxia, infecçāo, imunossupressão e as rejeiçōes.

DESCRITORES: Transplante cardiaco, humano, cuidados pós-operatórios. Transplante cardiaco, humano, pós-operatório, complicações. Transplante cardiaco, humano.

\section{CUIDADOS GERAIS}

Muito embora a técnica operatória do transplante cardiaco não tenha sofrido grandes alterações desde as suas primeiras aplicaçōes, os cuidados e as medidas de suporte pós-operatório foram sedes de grandes conquistas que, ao lado da ciclosporina, propiciaram a melhora dos resultados. As complicações que ocorrem após o transplante advêm, direta ou indiretamente, dos efeitos colaterais da imunossupressão, das rejeiçōes ou do próprio ato operatório $7,11,14,16$. O pós-operatório imediato é realizado em isolamento reverso, com desinfecção da unidade e dos equipamentos utilizados. Contudo, maiores benefícios são obtidos com a aplicação dos cuidados dispensados pela equipe de transplante no manuseio do paciente, empregando gorros, máscaras, aventais e, principalmente, a lavagem das mãos. Estas medidas são suspensas progressivamente, de acordo com a retirada dos cateteres, drenos e com a evolução clínica favorável do paciente.

\section{MONITORIZAÇÃO E EVOLUÇÃO HEMODINÂMICA}

Os cuidados imediatos não diferem significativamente daqueles adotados habitualmente em cirurgia cardíaca. Todavia, o transplante apresenta peculiaridades que requerem controle rigoroso do comportamento funcional do enxerto, possibilitando, desta forma, o diagnóstico precoce de eventuais anormalidades $\mathrm{e}$ as suas respectivas correçōes. A monitorização hemodinâmica invasiva, com o auxílio do cateter de Swan-Ganz, é de fundamental importância; associada à ecocardiografia bidimensional seriada, fornece importantes informações a respeito da adaptação anatômica e do comportamento funcional dos ventrículos.

O pós-operatório é marcado pela hipocontratilidade miocárdica transitória secundária às injúrias sofridas pelo coração transplantado devido à anóxia prolongada e à adaptação hemodinâmica do enxerto ao paciente. Esta disfunção temporária determi-

Trabalho realizado no Instituto do Coração do Hospital das Clínicas da Faculdade de Medicina da Universidade de Săo Paulo.

Recebido para publicação em fevereiro de 1996.

"Do Instituto do Coraçăo do Hospital das Clinicas da Faculdade de Medicina da Universidade de Săo Paulo.

Endereço para correspondência: Alfredo Inácio Fiorelli. Rua Morgado de Mateus, 126/81. CEP 04015-050. São Paulo, SP, Brasil. 
FIORELLI, A. I. \& STOLF, N. A. G. - Cuidados no pós-operatório do transplante cardíaco. $38,1996$.

na a redução do volume sistólico, de tal forma que a manutenção do débito cardíaco é garantido pelo aumento da freqüência cardíaca $3,7,11,13$. A recuperação do coração desnervado geralmente ocorre em uma semana. $\mathrm{O}$ uso de drogas inotrópicas (dopamina, dobutamina ou isoprenalina) e de vasodilatadores (nitroprussiato, nitroglicerina ou prostaglandina) constitui valioso recurso nesta fase de adaptação. A recuperação do ventrículo esquerdo invariavelmente precede a do direito. No Gráfico 1 encontra-se representada a evolução imediata das principais variáveis hemodinâmicas no transplante cardíaco ortotópico.

A hipertensão pulmonar pré-existente ou a sua exacerbação transitória após o transplante pode gerar profundo transtorno na evolução do paciente ${ }^{3}$. Este fato é responsável pela exclusão de candidatos ao transplante ortotópico com resistência pulmonar fixa superior a $6 \mathrm{U}$ Woods, devido ao alto risco de falência ventricular direita. Em 1990, PASCUAL et alii ${ }^{18}$ confirmaram as vantagens do uso de vasodilatadores nesta fase de adaptação, demonstrando a superioridade dos efeitos hemo-

\section{GRÁFICO 1}

COMPORTAMENTO HEMODINȦMICO EVOLUTIVO NO PRÉ TRANSPLANTE, NO DOADOR E NO PÓS-OPERATÓRIO IMEDIATO

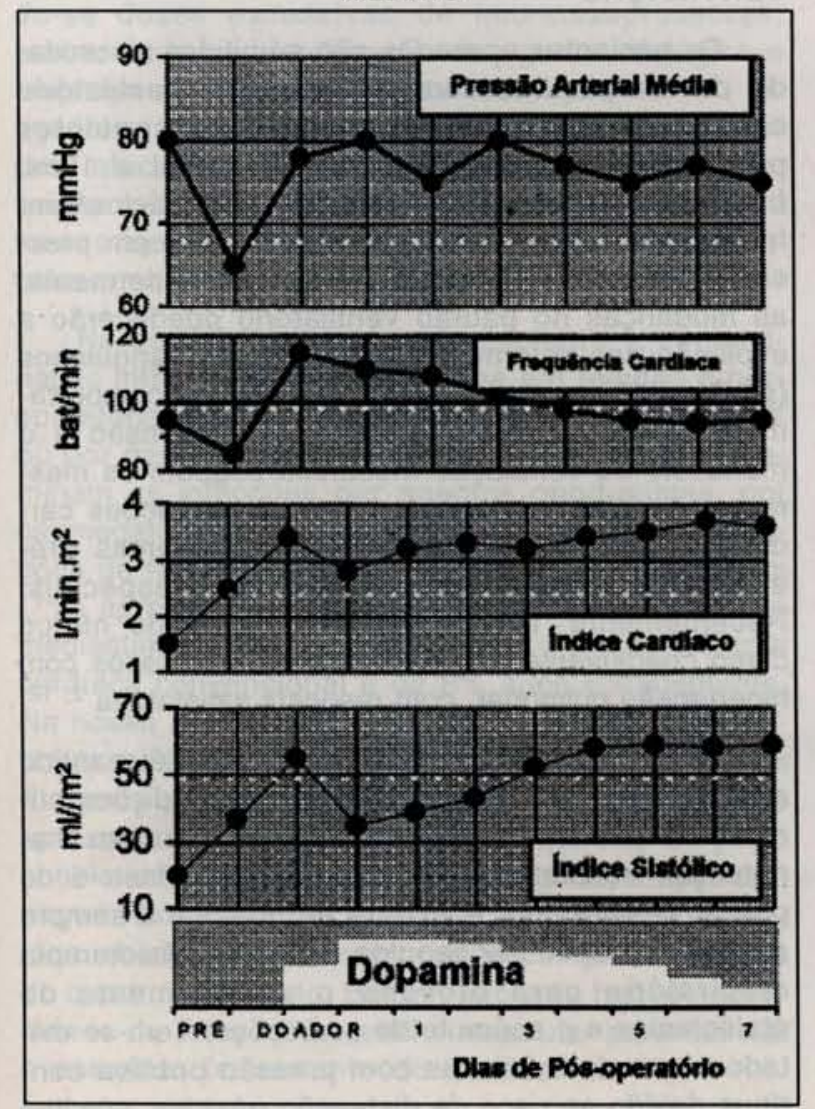

dinâmicos da prostaciclina em relação ao nitroprussiato $e$, deste, em relação à nitroglicerina ${ }^{18}$. A prostaciclina tem sido reservada somente aos casos mais graves e de difícil controle. A infusão contínua de drogas inotrópicas e vasodilatadores tem início no intra-operatório pouco antes da reperfusão miocárdica, sendo mantida até a completa adaptação do enxerto. A associação dos diferentes agentes inotrópicos e vasodilatadores tem sido recomendada, devido à potencialização de seus efeitos, e o seu manuseio tem sido orientado em função do padrão hemodinâmico evolutivo.

Em nossa casuística, temos observado alguns pacientes que evoluem normalmente com vasodilatação periférica acentuada, resistência vascular inferior a 500 dinas.seg. $\mathrm{cm}^{-5}$ e com débito cardíaco normal ou elevado. Possivelmente, este fenômeno seja secundário à liberação de substâncias vasoativas durante a circulação extracorpórea, sendo controlado com a administração de nor-adrenalina.

O aparecimento de baixo débito cardíaco que se acompanha de hipotensão arterial é crítico, devido à hipoperfusão sistêmica. Este problema torna-se ainda mais grave quando o enxerto é marcado por anóxia prolongada ou preservação deficiente. 0 emprego do balāo intra-aórtico é util nos casos com disfunção ventricular esquerda, devido ao importante papel no aumento da perfusão miocárdica e na redução do trabalho cardíaco. Na disfunção ventricular direita refratária ao tratamento clínico, recomenda-se a instalação precoce da assistência circulatória mecânica com bomba centrífuga. Na disfunção global do enxerto deverão ser considerados a assistência bi-ventricular e o retransplante 8,9 . A duração e a intensidade da terapia aplicada dependerão do dano sofrido pelo coração e da sua possibilidade de recuperação.

A liberação da enzima CKMB no transplante (Gráfico 2) pode elevar em até cinco vezes os seus

GRÁFICO 2

VARIAÇĀO DOS NIVEEIS SÉRICOS DA ENZIMA CKMB NO PÓS. OPERATORIO IMEDIATO DE TRANSPLANTE CARDIACO ORTOTOPICO.

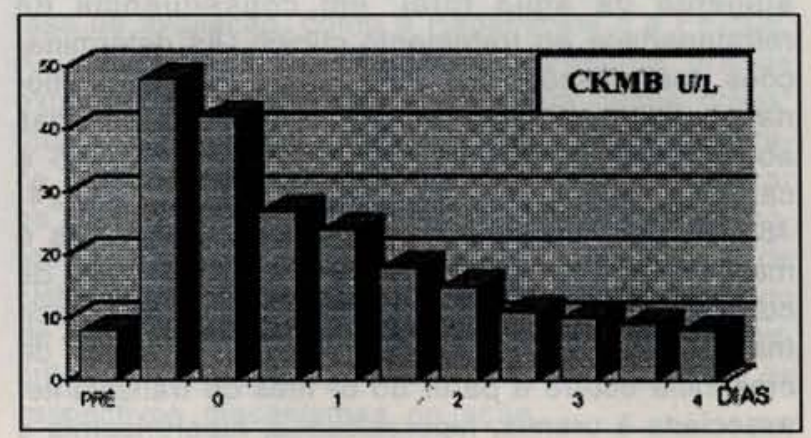


valores normais, devido a anóxia prolongada, maior número de secções e suturas, em relação às demais operações cardiacas.

A hipertensão arterial prejudica a recuperação do miocárdio, pelo aumento do trabalho sistólico e o consumo de oxigênio, tendo como gênese a interação de vários fatores: dor, liberação de catecolaminas, imunossupressão e outros $3,4,10$. 0 nitroprussiato é a droga de escolha no seu controle, sendo posteriormente substituído por outros vasodilatadores, entre eles, hidralazina, prasosin ou inibidores da enzima de conversão.

O coração transplantado exibe, via de regra, rítmo sinusal ou juncional. Usualmente é possível identificarem-se duas ondas $\mathrm{P}$ no eletrocardiograma. A primeira, isolada, refere-se ao nó sinoatrial do receptor e a segunda, seguida do complexo QRS, ao doador. As taquiarritmias supraventriculares ocorrem com relativa frequeência após o transplante e geralmente estão associadas aos episódios de rejeição, muito embora a fibrilação atrial e o flutter possam ocorrer na sua ausência. As arritmias ventriculares são menos freqüentes e geralmente são secundárias aos distúrbios metabólicos (hipopotassemia, hipomagnesemia, acidose ou hipotermia). As bradiarritmias estão presentes em mais de $50 \%$ dos casos neste período de adaptação, sendo atribuídas em sua maioria à disfunção do nó sinoatrial, porém, distúrbios na condução atrioventricular também podem ocorrer. Estas alteraçōes são secundárias aos efeitos da isquemia sobre o enxerto, do traumatismo cirúrgico, de anomalias da artéria do nó sinoatrial e dos episódios de rejeição. Quando a bradicardia é acentuada, impöe-se o emprego de estimulação cardíaca artificial temporária e, na sua persistência, indica-se o implante de marcapasso definitivo. Em nossa experiência, 12,3\% dos pacientes operados necessitaram de estimulação cardíaca temporária e $3,5 \%$ de definitiva.

\section{MONITORIZAÇÃO DOS FLUÍDOS E FUNÇÃO RENAL}

Muitos pacientes chegam ao transplante com aumento da água total, em consequeência da refratariedade ao tratamento clínico. As determinações das pressões em átrio direito, artéria pulmonar, capilar pulmonar e artéria radial, associadas aos valores do balanço hídrico, débito urinário e cardiaco, orientam a reposição volêmica. Até 24$48 \mathrm{~h}$ de pós-operatório a restrição de cristalóides é mais acentuada, dando-se prefêrencia à infusão de colóides e procurando-se manter o hematócrito acima de $35 \%$. A elevação progressiva nas taxas de creatinina ocorre a partir do $6^{2}$ mês de transplante, associada à uremia, hipercalcemia, hiperuricemia e queda de excreção urinária de sódio. A nefropatia é inevitável nos pacientes em uso de ciclosporina, podendo ser atenuada com a redução da imunossupressão ${ }^{16}$.

O desenvolvimento de insuficiência renal modifica a evolução natural do transplante, sendo, geralmente, secundária às alterações hemodinâmicas e potencializada pela ciclosporina. A diálise está indicada nos casos mais graves para controlar a volemia e o metabolismo. A introdução da ciclosporina a partir do $2^{\circ}$ dia de transplante ou após a estabilização hemodinâmica tem reduzido sensivelmente a incidência desta complicação. $O$ papel da ciclosporina na fisiopatologia da nefropatia é controversa e multifatorial; admite-se que ocorra vasoconstrição da arteríola eferente associada à toxicidade direta nos túbulos renais e a perda de função do néfron predisponha ao aparecimento de hipertensão arterial. Inicialmente, esta disfunção é reversivel e dose dependente, tornando-se, mais tarde, irreversível. Entre os mediadores que participam da vasoconstrição renal destacam-se as prostaglandinas, a endotelina, bem como a ação direta da ciclosporina no tônus da musculatura lisa dos vasos $11,14,16$

\section{VENTILAÇÃO}

Os pacientes operados são admitidos na unidade de terapia intensiva com suporte ventilatório ciclado a volume, mantendo-se os seguintes parâmetros: volume corrente entre $10 \mathrm{ml}$ e $15 \mathrm{ml}$, freqüência respiratória entre 15 a $20 \mathrm{ciclos} / \mathrm{min}$, fração inspiratória de $\mathrm{O}_{2}$ acima de $60 \%$ com pressão inspiratória final de $5 \mathrm{cmH}_{2} \mathrm{O}$. Posteriormente, as mudanças no padrão ventilatório obedecerão a evolução das determinações dos gases sangüineos $\left(\mathrm{pAO}_{2}>80 \mathrm{mmHg}\right.$ ), padrão radiológico, comportamento clínico e hemodinâmico. A suspensão e o manuseio da ventilação mecânica seguem os mesmos princípios adotados em outras operações cardíacas; contudo, a existência de problemas préexistentes podem requerer cuidados especiais. Recentemente, tem-se associado o óxido nítrico como coadjuvante aos vasodilatores nos casos com hipertensão pulmonar, com resposta satisfatória ${ }^{2,12}$.

Via de regra, o suporte ventilatório é mantido nas primeiras 12 horas, até que as condições clinicas do paciente permitam a extubação com manutenção satisfatória da oxímetria sangüinea e do padrão respiratório. A extubação precoce é sempre desejável e deve ser seguida de intensa fisioterapia respiratória para prevenir o aparecimento de atelectasias e o acúmulo de secreções. Tem-se evitado o uso de máscaras com pressão positiva contínua devido ao risco de distensão gástrica, vómitos 
e broncoaspiração. O emprego de ventilação mandatória intermitente auxilia o processo de extubação, principalmente nos casos de suporte prolongado.

\section{ANTIBIOTICOPROFILAXIA E INFECÇÕES}

A cardiopatia, a disfunção leucocitária secundária à circulação extracorpórea, a agressão cirúrgica e, principalmente, o uso de imunossupressores são os principais fatores que interferem na imunidade do paciente. A combinação destes fatores associada às diferentes vias de entrada aos agentes microbianos predispõe às infecções, em especial aos organismos oportunistas. Temos empregado o cefuroxime na antibioticoprofilaxia, com início no pré-operatório e mantido até a retirada completa de cateteres e drenos. A antibioticoterapia, sempre que possível, deve ser orientada pela identificação do agente responsável e pela sua sensibilidade.

Devido ao bloqueio da resposta imunitária, os sinais ou sintomas usualmente presentes nos processos infecciosos podem estar abolidos. A infecção é uma das principais causas de óbito e o uso de drogas mais específicas, como a ciclosporina e a FK-506, não modificaram este comportamento ${ }^{14}$. A adoção de medidas preventidas tem reduzido a sua incidência: melhor controle da rejeição evitando-se doses excessivas de imunossupressores, precocidade na identificação do agente etiológico e emprego de métodos de alta resolução no seu diagnóstico. A distribuição da incidência dos processos infecciosos acompanha a curva de rejeição, sendo mais freqüênte e mais grave nos primeiros meses após o transplante, pois, nesta fase, a imunossupressão é mais intensa.

No período imediato ao transplante, a contaminação intra-operatória predomina em relação à peroperatória, ocasionadas geralmente por estafilococos ou por germes gram negativos. Tardiamente predominam as infecçöes por agentes oportunistas, por citomegalovírus, pneumocístis e fungos. As infecçōes da ferida operatória embora pouco freqüêntes (7\%) apresentam alta mortalidade. A incidência de mediastinite é da ordem de $0,4 \%$ a $4,5 \%$ em cirurgia cardíaca convencional e de $8 \%$ após o transplante. $\mathrm{Na}$ nossa experiência, $2(1,4 \%)$ pacientes apresentaram mediastinite, sendo o Staphylococcus aureus o agente patogênico responsável. Ambos os casos apresentaram resolução total do quadro, exigindo antibioticoterapia específica prolongada, ampla drenagem cirúrgica com manutenção da ferida operatória aberta e fechamento após completo controle do quadro infeccioso. Em um paciente houve necessidade de rotação de retalho muscular para facilitar o completo fechamento do mediastino.
A antibioticoprofilaxia tem sido proposta para infecções especificas; assim, nos primeiros meses após o tratamento da rejeição aguda, a pirimetamina e o trimetropim-sulfametoxazol têm sido empregados na prevenção da toxoplasmose e da pneumocistose, respectivamente. Nos casos de infecção por citomegalovírus a profilaxia com aciclovir, ganciclovir ou imunoglobulina é controversa, apesar desta infecção estar associada a alta morbidade e mortalidade. Todavia, quando o doador apresenta sorologia positiva para o citomegalovírus e o receptor negativa a profilaxia está indicada, considerando-se o risco de $25 \%$ a $45 \%$ do aparecimento da forma clínica de infecção.

Em estudo multicêntrico ${ }^{15}$, onde foram analisadas somente as infecções graves que necessitaram de terapia oral ou endovenosa, observou-se incidência de 0,5 epsódios de infecção/paciente/ano, após o transplante cardíaco. Verificou-se, também, que $68 \%$ dos pacientes não apresentaram infecção, $21 \%$ tiveram um episódio de infecção e $11 \%$ deles apresentaram mais de um episódio de infecção. Em nossa Instituição, analisando-se os primeiros 100 pacientes operados e considerando-se qualquer episódio de infecção, encontou-se que $60 \%$ dos pacientes apresentaram pelo menos um quadro infeccioso no primeiro mês após o transplante, reduzindo para $29 \%$ no segundo mês e para $8 \%$ no terceiro mês de evolução. As bactérias foram os principais agentes etiológicos, seguidas dos vírus e fungos, enquanto que o trato respiratório foi o principal sítio de infecção, seguido da pele e mucosas.

\section{IMUNOSSUPRESSÃO}

O fenômeno de rejeição é controlado pelo bloqueio do sistema imune com drogas específicas, porém, acompanhado de efeitos colaterais. Inúmeros estudos têm-se dedicado a pesquisas de imunossupressores potentes e com ação específica; contudo, ainda não dispomos de um imunossupressor ideal. A ciclosporina foi introduzida na prática clínica em 1980 e atualmente está presente em todos os protocolos de imunossupressão 7,11 , fazendo excessão àqueles que utilizam novas drogas em fase de avaliação, como a Rapamicina e a FK-506. A Universidade de Pittsburgh apresenta grande experiência clínica com o uso desta última droga; todavia, apesar de potente imunossupressor, oferece efeitos adversos significativos ${ }^{1}$. Para minimizar os efeitos colaterais dos imunossupressores os protocolos atuais utilizam basicamente a associação de ciclosporina, corticóide e azatioprina, denominado de esquema tríplice. Na Tabela 1 encontram-se descritos os principais agentes imunossupressores e os respectivos mecanismos de ação. 
FIORELLI, A. I. \& STOLF, N. A. G. - Cuidados no pós-operatório do transplante cardíaco. 38,1996 .

TABELA 1

AGENTES IMUNOSSUPRESSORES

\begin{tabular}{|c|c|}
\hline IMUNOSSUPRESSOR & $A C ̧ \bar{A} O$ \\
\hline CICLOSPORINA & $\begin{array}{l}\text { Bloqueio mais acentuado na proliferação de linfócitos-T do que B. Bloqueia a } \\
\text { liberação de interleucina-1 dos macrófagos ativados e a interleucina-2 dos } \\
\text { linfócitos-THelper. }\end{array}$ \\
\hline \multicolumn{2}{|l|}{ CORTICOSTERÓIDE } \\
\hline Prednisona & $\begin{array}{l}\text { Bloqueia o sistema imunitário em várias fases. Inibe a proliferação de linfócitos- } \\
\text { T pelo bloqueio da liberação de interleucina-1. Diminui o número de linfócitos-T } \\
\text { pela diminuição da resposta aos antígenos. }\end{array}$ \\
\hline Metilprednisolona & $\begin{array}{c}\text { Ação semelhante à prednisona, porém, com propriedade antiinflamatória duas } \\
\text { vezes maior. }\end{array}$ \\
\hline AZATIOPRINA & $\begin{array}{c}\text { Trata-se de uma purina derivada do 6-mercaptopurina, interfere na atividade } \\
\text { das células T, não interfere na produção de anticorpos. Deprime todos os } \\
\text { elementos da medula óssea, produzindo leucopenia. }\end{array}$ \\
\hline $\begin{array}{l}\text { (*)GLOBULINA } \\
\text { ANTITIMOCITICA (ATG)e } \\
\text { ANTILINFOCÍTICA (ALG) }\end{array}$ & $\begin{array}{l}\text { Trata-se de imunoglobulinas, derivadas do soro de cobaia ou cavalo, que } \\
\text { reduzem o número de linfócitos-T circulantes, em taxas abaixo de } 10 \% \text { do } \\
\text { normal. }\end{array}$ \\
\hline $\begin{array}{l}\left({ }^{*}\right) \text { ANTICORPOS } \\
\text { MONOCLONAL (OKT-3) }\end{array}$ & $\begin{array}{l}\text { Anticorpos específicos contra linfócitos-T, podendo removê-los de circulação } \\
\text { rapidamente. Não apresentam efeitos nos demais elementos do sangue. }\end{array}$ \\
\hline
\end{tabular}

(*) Utilizados somente em situações especiais.

A diferença entre os diversos protocolos de imunossupressão reside na quantidade e no manuseio das drogas empregadas. A Tabela 2 apresenta o protocolo atual adotado em nossa Instituição. A ciclosporina somente é introduzida no $1^{\circ}$ ou $2^{\circ}$ dia de pós-operatório, desde que a função renal e o estado hemodinâmico estejam preservados, sendo suspensa temporariamente na presença de qualquer sinal de disfunção renal. Nestes casos tem-se associado imunoglobulina antitimocitária (ATG) ou antilinfocitária (ALG) na dose de $10 \mathrm{mg} / \mathrm{kg}$ de peso corpóreo, por período de até duas semanas, ajus- tando-se a dose em função do número de linfócitos. Os anticorpos monoclonais contra linfócitos T3 (OKT3) também podem ser utilizados com beneficios controversos. Tardiamente, a imunossupressão é reduzida progressivamente, em função da evolução clínica e dos resultados das biópsias.

O protocolo apresentado na Tabela 2 pode ser modificado em função da evolução clínica, em especial, nas rejeições, infecções, hiperglicemia persistente e nas neoplasias. Durante os episódios de rejeição (moderada-severa), como demonstra a

TABELA 2

PROTOCOLO DE IMUNOSSUPRESSÃO

\section{CICLOSPORINA} CORTICOSTERÓIDES

ATG $1^{\circ}$ ou $2^{\circ}$ dia após o transplante Após a realimentaçăo Manutenção

Pré-operatório Pós-operatório Imediato Manutenção

Intra-operatório

$1^{2}$ ou $2^{\circ}$ dia de pós-operatório Após a realimentação Manutençăo

Situaçōes especiais

\section{$1 \mathrm{mg} / \mathrm{kg} / \mathrm{dia}$ EV em 8 horas \\ 3 a $5 \mathrm{mg} / \mathrm{kg} / \mathrm{dia}$ VO \\ 3 a $5 \mathrm{mg} / \mathrm{kg} / \mathrm{dia}$ VO}

$3 \mathrm{mg} / \mathrm{kg}$ VO 2 horas antes 3 a $4 \mathrm{mg} / \mathrm{kg} / \mathrm{dia}$

$3 \mathrm{mg} / \mathrm{kg} /$ dia com Leucócitos $>4000$

\section{$500 \mathrm{mg}$ de Metil-prednisolona EV $10 \mathrm{mg} / \mathrm{kg}$ de Metil-prednisolona Prednisona $1 \mathrm{mg} / \mathrm{kg} / \mathrm{dia}$} 0,1 a $0,2 \mathrm{mg} / \mathrm{kg} / \mathrm{dia}$

10 a $15 \mathrm{mg} / \mathrm{kg} / \mathrm{dia}$ EV durante 15 dias $5 \mathrm{mg} /$ dia EV durante 14 dias

EV - Endovenoso Vo - Via Oral 
FIORELLI, A. I. \& STOLF, N. A. G. - Cuidados no pós-operatório do transplante cardíaco. Rev. Bras. Cir. Cardiovasc., 11 (1):30$38,1996$.

Tabela 3; utiliza-se a pulsoterapia endovenosa e nos casos refratários tem-se associado as drogas linfocíticas (ATG ou OKT3) ou o Metotrexate, com resultados satisfatórios.

\section{REJEIÇĀO AGUDA E HIPERAGUDA}

A rejeição representa a resposta imune normal do hospedeiro em presença de antígenos estranhos ao organismo. A despeito de maiores conhecimentos sobre a imunossupressão, a rejeição leva à destruição do órgão e continua sendo uma importante causa de óbito no pós-operatório imediato e no primeiro ano após o transplante. No coração, a rejeição aguda pode ser mediada, tanto pela ativação ou formação de linfócitos (rejeição celular), quanto por anticorpos (rejeição humoral), sendo esta última menos freqüente. A distinção entre elas nem sempre é evidente, coexistindo ambos os mecanismos no mesmo processo, ou seja, pode-se identificar tanto a produção de anticorpos dirigidos contra as células do doador como a agressão celular direta ao enxerto.

A rejeição hiperaguda é uma forma grave de rejeição humoral e ocorre em poucas horas ou mesmo imediatamente após a reperfusão coronária do coração, determinando a destruição e falência imediata do enxerto. Nestes casos, o receptor apresenta anticorpos pré-formados contra antígenos do doador; a resposta é basicamente humoral e a falência do enxerto geralmente ocorre em curto espaço de tempo. Estes anticorpos resultam usualmente da exposição prévia aos antígenos por gravidez ou transfusão sangüínea. Deve-se ressaltar que este tipo de rejeição pode ocorrer mesmo na ausência de imcompatibilidade $\mathrm{ABO}$ ou de anticorpos antiHLA, pois são mediados por anticorpos citotóxicos dirigidos contra o sistema endotelial. Este tipo de rejeição em transplante cardíaco é raro, não é passível de tratamento, é irreversível e raramente se consegue realizar o retransplante. Sua incidência pode ser, ainda, reduzida mediante o estudo prévio do grau de sensibilização alogênica do receptor (painel de linfócitos) e pela prova cruzada específica (cross-match), especialmente nos pacientes sensibilizados (painel > 10\%).

Os episódios de rejeição aguda são fundamentalmente celulares e caracterizados por infiltração linfóide no coração, aparecendo em geral a partir da primeira semana após o transplante. A expressão anatomopatológica é caracterizada pela quantidade de infiltrado linfocitário, presença de miocitólise e pelo tecido cicatricial fibroso.

A destruição dos diferentes tipos histopatológi$\cos ^{4}$ encontrados em biopsias endomiocárdicas demonstra que a maior incidência dos episódios de rejeição ocorre nos primeiros meses após o transplante e a rejeição classificada como severa aparece com menor incidência. Nossos resultados não diferem daqueles apresentados na literatura, onde cerca de $30 \%$ dos pacientes apresentam pelo menos um episódio de rejeição no primeiro mês de transplante. Após o primeiro ano, tornam-se gradativamente menos freqüentes e de mais fácil controle. Em estudo multicentrico recentemente publicado, observou-se que a rejeição foi responsável por $17 \%$ dos óbitos após o transplante e que apenas $37 \%$ dos pacientes não apresentaram rejeição que exigisse tratamento ${ }^{13}$. Vários fatores de risco têm sido relacionados à rejeição, destacando-se: número de incompatibilidade HLA, receptor jovem do sexo feminino, coração doador proveniente de mulher jovem, doador de grupo sangüineo não $\mathrm{O}$, painel de linfócitos maior que $10 \%$, prova cruzada positiva e infecção por citomegalovírus, atribuindo-se maior importância aos dois primeiros fatores.

A despeito da introdução da ciclosporina, não houve redução da incidência de rejeição aguda, porém, os episódios tornaram-se mais benignos, com pouca repercussão hemodinâmica $e$ de mais

TABELA 3

ORIENTAÇĀO NA IMUNOSSUPRESSÃO DURANTE OS EPISÓDIOS DE REJEIÇĀO AGUDA

\section{Rejeição Discreta Persistente}

Aumento nas doses do Corticóide, da Azatioprina ou da Ciclosporina

\begin{tabular}{|c|c|c|}
\hline \multicolumn{3}{|c|}{ Aumento nas doses do Corticóide, da Azatioprina ou da Ciclosporina } \\
\hline \multicolumn{3}{|c|}{ 2. Rejeiçāo Moderada } \\
\hline $\begin{array}{c}\text { No Primeiro } \\
\text { Trimestre } \\
\text { Qualquer Época }\end{array}$ & $\begin{array}{l}\text { Sem Alteração da } \\
\text { Função } \\
\text { Com Alteração da } \\
\text { Função }\end{array}$ & $\begin{array}{c}\text { Pulsoterapia com } 2 \mathrm{mg} / \mathrm{kg} \text { de Prednisona VO e } \\
\text { redução de } 20 \mathrm{mg} \text { a cada } 3 \text { dias } \\
\text { Pulsoterapia com } 1,0 \mathrm{~g} / \text { dia de Metil-prednisolona EV } \\
\text { por } 3 \text { dias e posterior redução }\end{array}$ \\
\hline
\end{tabular}

3. Rejeição Severa

Pulsoterapia Endovenosa ou ATG/OKT3 
fácil controle. Este fato deve-se, entre outros, à redução do edema inflamatório no miocárdio durante a rejeição, conferindo, desta forma, à biopsia endomiocárdica destaque especial no seu diagnóstico.

A técnica adotada na biopsia endomiocárdica do ventrículo direito é aquela proposta por CAVES et alii ${ }^{6}$, em 1974 , com a retirada de fragmentos do septo interventricular. Em situações especiais, como nas tromboses venosas, outras vias podem ser utilizadas, tais como: jugular e subclávia esquerdas ou as femorais. Nos casos críticos, onde o transporte à sala de hemodinâmica oferece risco ao paciente, a biopsia tem sido realizada à beira do leito, sob orientação da ecocardiografia bidimensional. Via de regra, a periodicidade deste método tem obedecido a seguinte orientação, em função do tempo de pós-operatório: semanal no primeiro mês, quinzenal até o terceiro mês, mensal ou bimensal até o primeiro ano e, a seguir, a cada dois ou três meses.
Vários métodos não invasivos têm sido propostos no diagnóstico da rejeição; contudo, nenhum deles demonstrou sensibilidade e especificidade superior a $80 \%-90 \%$ em relação à biopsia endomiocárdica. Estes métodos baseiam-se em alterações da função miocárdica ou a detecção de alguma alteração na ativação do sistema imune durante a rejeição 5,10 . Em crianças, especialmente, pelas dificuldades técnicas do uso seriado das biopsias, a monitorização da rejeição, tem se apoiado no estudo ecocardiográfico. Em nosso Serviço foram desenvolvidos protocolos especiais de avaliação ecocardigráfica e de cintilografia com Gálio-67, merecendo menção especial este último pela sua alta sensibilidade e especificidade.

\section{ALTERAÇÕES GASTRINTESTINAIS}

O trato digestivo pode ser sede de diversas complicações após o transplante cardíaco, exacer-

FIORELLI, A. I. \& STOLF, N. A. G. - Cuidados no pós-operatório do transplante cardiaco. Rev. Bras. Cir. Cardiovasc., 11 (1):30$38,1996$.

badas ou não pela imunossupressão. A gastrite e a úlcera péptica podem aparecer ou serem reativadas pelo uso do corticóide ou pelas infecções, em especial o citomegalovírus. Tem-se encontrado correlação estreita entre o tempo de aparecimento destas complicaçōes abdominais e o uso da pulsoterapia. A profilaxia com bloqueadores $\mathrm{H} 2$ e antiácidos, particularmente nos pacientes de risco, reduzem a incidência destas complicações. $\mathrm{O}$ estômago é rotineiramente drenado com sonda nasogástrica, durante o período de intubação orotraqueal, evitando-se, assim, a distenção do tubo digestivo, em consequêencia do hipoperistaltismo transitório. Devese salientar que as úlceras pépticas, ao lado dos divertículos dos cólons, podem perfurar e determinar quadro clínico grave de peritonite, muitas vezes atenuado pela inibição da resposta inflamatória.

As infecções ocasionadas por Candida albicans, herpes simples e fungos podem acometer o trato digestivo alto, produzindo disfagia de graus variáveis, cujo diagnóstico deve ser confirmado pela endoscopia com biopsia para a instalação de terapêtica adequada.

A pancreatite aguda após o transplante ocorre com freqũência variável entre $2 \%$ a $18 \%$ e, quando intensa, apresenta alta morbidade e mortalidade. Os fatores predisponentes são: hipoperfusāo esplênica, doença biliar ou pancreática prévia, infecção por citomegalovírus ou pela ação das drogas imunossupressoras, em especial a ciclosporina e a azatioprina. A circulação extracopórea pode ser responsável pelo aparecimento de hiperamilasemia sem dor abdominal intensa ou mesmo sinais clínicos de pancreatite. O tratamento via de regra é clínico, sendo monitorizado com ultra-sonografia ou tomografia computadorizada. Igualmente, as anomalias hepato-biliares ocorrem com relativa freqüên- cia, ocasionadas pela hepatite $B$, hepatite por citomegalovírus ou ação dos imunossupressores. Em nossa experiência, $15,9 \%$ dos pacientes desenvolvem colecistite no pós-operatório; assim sendo, sempre que possível, a colecistectomia laparoscópica tem precedido o transplante.

A função hepática pode estar alterada no préoperatório em decorrência da congestão passiva crônica, sendo geralmente reversível com a melhora do débito cardíaco após o transplante. Contudo, a hepatotoxicidade da imunossupressão, em especial a azatioprina e a ciclosporina, pode ser responsável pela elevação transitória inicial das enzimas hepáticas e das bilirrubinas. A ciclosporina predispõe à estase biliar, com elevação, em geral, da bilirrubina direta e da fosfatase alcalina. Outros fatores podem alterar a função hepática, tais como: outras drogas, infecção e baixo débito cardíaco. No Gráfico 3 encontra-se representado o comportamento das enzimas hepáticas e das frações de proteinas no pós-operatório imediato ao transplante.

\section{OUTRAS COMPLICAÇÕES}

Pacientes portadores de operação cardíaca prévia, disfunção hepática e valores anormais dos tempos de coagulação apresentam maior risco de sangramento no pós-operatório e exigem cuidados técnicos adicionais.

As alterações neurológicas comumente observadas em cirurgia cardíaca podem estar presentes após o transplante. As anormalidades mais freqüentes são a confusão mental, alterações motoras e convulsões, devido a distúrbios eletrolíticos, hipóxia, microembolias ou exacerbadas pela ciclosporina.

FIORELLI, A. I. \& STOLF, N. A. G. - Early postoperative care of heart transplantation. Rev. Bras. Cir. Cardiovasc., 11 (1): 30-38, 1996.

ABSTRACT: The authors describe principal aspects involved in early postoperative period of heart transplantation, to emphasize: postoperative monitoring, hemodynamic evaluation, arrhythmias, fluid management, gastrointestinal system, renal system, ventilatory support, antibiotic prophylaxis, infection, immunosuppression, and rejection.

DESCRIPTORS: Heart transplantation, human, postoperative care. Heart transplantation, human, postoperative complications. Heart transplantation, human. 


\section{REFERÊNCIAS BIBLIOGRÁFICAS}

1 ARMITAGE, J. M.; FRICKER, F. J.; del NIDO, P. - A decade (1982-1992) of pediatric cardiac transplantation and the impact of FK506 immunosuppression. J. Thorac. Cardiovasc. Surg., 105: 464-473, 1993.

2 AULER, J. O. C.; CARMONA, M. J.; BOCCHI, E.; BACAL, F.; FIORELLI, A. I.; STOLF, N. A. G.; JATENE, A. D. - Low doses of inhaled nitric oxide in patients submitted to heart transplantations. $J$. Heart Lung Transplant. (no prelo)

3 BHATIA, S. J.; KIRSHENBAUN, J. M.; SHEMIN, R. J.; COHN, L. H.; COLLINS, J. J.; DI SESA, V. J.; YOUNG, P. J.; MUDGE, Jr. G. H. ; SUTTON, M. G. - Time course of resolution of pulmonary hypertension and right ventricular remodeling after orthotopic cardiac transplantation. Circulation, 76: 819-826, 1987.

4 BILLINGHAM, M. E.; CARY, N. R. B.; HAMMOND, M. E.; KEMNITZ, J.; MARBOE, C.; MCCALLISTER, $H$. A.; SNOVAR, D. C.; WINTERS, G. L.; ZERBE, A. A working formulation for the standardization of nomenclature in the diagnosis of heart and lung rejection: heart rejection study group. J. Heart Transplant., 9: 587-601, 1990.

BOLLING, S. F.; PUTNAM Jr., J. B.; ABRAMS, G. D.; McKAY, A. M.; DEEB, G. M. - Hemodinamics versus biopsy findings during cardiac transplant rejection. Ann. Thorac. Surg., 51: 52-55, 1991.

6 CAVES, P. K.; BILLINGHAM, M. E.; STINSON, E. B.; SHUMWAY, N. E. - Serial transvenous biopsy of the transplanted human heart: improved management of acute rejection episodes. Lancet, 2: 821, 1974.

7 DAWKINS, K. D.; OLDERSHAW, P. J.; BILLINGHAM, M. E.; HUNT, S. A.; OYER, P. E.; JAMIESON, S. W.; POPP, R. L.; STINSON, E. B.; SHUMWAY, N. E. Changes in diastolic function as a noninvasive marker of cardiac allograft rejection. Heart Transplant., 3: 286-294, 1984.

8 FIORELLI, A. I. - Contribuição ao estudo da função do ventrículo esquerdo no pós-operatório de transplante cardíaco. São Paulo, 1992, [Tese. Doutorado. Faculdade de Medicina da Universidade de São Paulo].

9 FIORELLI, A. I.; STOLF, N. A. G.; MULINARI, L.; SABINO NETO, A.; MOREIRA, L. F. P.; AULER Jr., J. O.; BOCCHI, E.; SEFERIAN Jr., P.; MORAES, A.; JATENE, A. D. - Circulaçāo assistida em disfunçōes de ventrículo direito após transplante cardíaco. In:
Congresso Latino-Americano de Transplantes, 6., Porto Alegre, 1991. Resumo dos trabalhos. Porto Alegre, 1991. p. 17.

10 FORSTER, T.; McGHIE, J.; RIJSTERBORGH, H.; VAN DE BORDEN, S.; LAIRD-MEETER, K.; BALK, A.; ESSED, C.; ROELANDT, J. - Can we assess the changes of ventricular filling resulting from acute allograft rejection with Doppler echocardiography? J. Heart Transplant., 7: 430-434, 1988.

11 GRATTAN, M. T.; MORENO-CABRAL, C. E.; STARNES, V. A.; OYER, P. E.; STINSON, E. B.; SHUMWAY, N. E. - Eight-year results of cyclosporine treated patients with cardiac transplants. J. Thorac. Cardiovasc. Surg., 99: 500-509, 1990.

12 JENSEN, N. K.; RICKSTEN, S. E.; STERQUIST, O.; BERGLE, C. H.; LINDELOV, B.; WENNMALM, A.; WAAGSTEIN, F.; LUDIN, J. - Inhaled nitric oxide in the evaluation of heart transplantation candidates with elevated pulmonary vascular resistence. J. Heart Lung Transplant., 13: 366-375, 1994.

13 KIRKLIN, J. K.; NAFTEL, D. C.; KIRKLIN, J. W.; BLASKSTONE, E. H.; WILLIANS, C. W.; BOUGER, R. C. - Pulmonary vascular resistance and the risk of heart transplantation. J. Heart Transplant., 7: 331 336, 1988.

McGREGOR, C. G. A.; JAMIESON, S. W.; OYER, P. E. - Heart transplantation at Stanford University. Heart Transplant., 4: 30, 1984.

MILLER, L. W.; NAFTAL, D. C.; BOURGE, R. C.; KIRKLIN, J. K.; BROZENA, J. C.; JARCHO, J.; HOBBS, R. E.; MILLS, R. M. - Infection after heart transplantation: a multiinstitutional story. J. Heart Lung Transplant., 13: 381-393, 1994.

MYERS, B. D.; ROSS, J.; NEWTON, L.; LUETSCHER, J.; PERLROTH, M. - Cyclosporine associated chronic nephropathy. N. Engl. J. Med., 311, 699-705, 1984.

OAKS, T. E.; PAE, W. E.; MILLER, C. A.; PIERCE, W. S. - Combined registry for the clinical use of mechanical ventricular assist pumps and the total artificial heart in conjunction with heart transplantation. Fifth official report - 1990. J. Heart Lung Transplant., 10: 621-625, 1991.

18 PASCUAL, J. M. S.; FIORELLI, A. I.; BELLOTTI, G. M.; STOLF, N. A. G.; JATENE, A. D. - Prostacyclin in the management of pulmonary hypertension after heart transplantation. J. Heart Transplant., 9: 644$651,1990$. 